\title{
Situação-limite e potência de ação: Atuação preventiva crítica em psicologia escolar
}

Ana Paula Gomes Moreira. Universidade de Mogi das Cruzes.

Raquel Souza Lobo Guzzo. Pontifícia Universidade Católica de Campinas.

\section{Resumo}

Falar sobre a trajetória que consolida a Psicologia Escolar no interior do movimento de crítica à estrutura e à dinâmica da sociabilidade capitalista é assunto recorrente, embora sempre pertinente. No entanto, entender que a delimitação do conteúdo da ação crítica do psicólogo escolar não é, ou pelo menos não tem sido, consequência imediata desta trajetória é um desafio urgente. Neste sentido, este trabalho soma-se às iniciativas que vem demonstrando, na prática, o que significa a atuação crítica do psicólogo escolar. Apresentamos aqui uma síntese da nossa proposta: materializar o conteúdo da atuação crítica do psicólogo escolar por meio do conceito de situação-limite desenvolvido por Martín-Baró no interior da Psicologia Social da Libertação e enfatizar o papel da escola como palco desta atuação.

Palavras-chave: psicologia escolar; psicologia social da libertação; atuação, crítica.

\begin{abstract}
Limit-situation and potent actions: Critical intervention is school psychology. Talking about the history that consolidates the School Psychology within the critical movement to the structure and dynamics of capitalist sociability is a recurring subject, but always relevant. However, understand that the definition about what means the critical action of the school psychologist is not clear yet continues to be an urgent challenge. Thus, this work adds to initiatives which puts in practice, which means the critical role of the school psychologist. Here we present a summary of our proposal: materialize the contents of the critical role of the school psychologist through the concept of limit-situation developed by Martin-Baró in the framework of Liberation Social Psychology and emphasize the role of the school as the place of this action.
\end{abstract}

Keywords: school psychology; liberation social psychology; agency; critical.

\section{Resumen}

Situación-límite y potencia de acción: Actuación crítico preventiva en psicología escolar. Hablar de la historia que consolida la Psicología Escolar dentro del movimiento crítico de la estructura y dinámica de sociabilidad capitalista es un tema recurrente, pero siempre relevante. Sin embargo, comprender que la definición de la acción crítica del psicólogo en la escuela no es, o al menos no ha sido, consecuencia inmediata de esta tendencia es un reto urgente. Por lo tanto, este trabajo se suma a las iniciativas que pone en práctica, es decir el papel fundamental del psicólogo escolar. Aquí presentamos un resumen de nuestra propuesta: materializar el contenido de la función esencial del psicólogo en la escuela a través del concepto de situación-límite desarrollado por Martín-Baró dentro de la Psicología Social de la Liberación y destacamos el papel de la escuela como lugar de celebración de esta acción.

Palabras clave: psicología escolar; psicología social de la liberación; actuación; critica. 
A história que revela a Psicologia Escolar como área que consolida um importante movimento de Crítica no interior da Psicologia Brasileira, foi contada e recontada na vida vivida e na vida escrita daqueles que se dedicaram à constituição da interface entre a Psicologia e a Educação (Angelucci, Kalmus, Paparelli, \& Patto, 2004; Facci, Eidt, \& Tuleski, 2006; Guzzo, 2007; Patto, 1984; Tanamachi, 2007). A literatura, fruto desta história, explicita pelo menos dois conteúdos atribuídos ao sentido desta Crítica: a gestação da ciência psicológica no berço da sociabilidade capitalista e a sua decorrente organização de práticas fragmentadas destinadas à manutenção ou reprodução das dimensões exigidas por esta sociabilidade.

No entanto, a despeito do seu valor de denúncia e das transformações que efetivamente aconteceram no campo da relação entre a Psicologia e a Educação, a reprodução desta história não assegurou que o sentido desta Crítica irrompesse na construção de práticas efetivamente coerentes e reveladoras do seu conteúdo. Possivelmente, esta conjuntura expressa o desafio permanente de perpetrar ações de mudança no interior da sociabilidade que, apesar de disfarçada e repaginada, continua sendo, insistente e cruelmente, mais do mesmo.

Acontece que o paradoxo é ainda mais premente quando consideramos que esta Crítica, assim contextualizada, não nos permite recuar, muito menos adotar a posição de quem espera a construção da nova sociedade para, depois, oferecer suas ações libertadoras. No sentido marxista, a ação que materializa a crítica é a única capaz de promover mudança (Paulo Netto, 1997). Mas, não sejamos imprudentes: esta ação não é força independente; é cotidiana, coletiva, consciente. Portanto, na prática da Psicologia Escolar, o sentido da crítica não pode ser menos evidente: o desenvolvimento humano não é processo espontâneo, a sua direção é fruto de ação determinante.

Desta compreensão, decorre a delimitação da escola como o espaço concreto que possibilita a materialização desta ação (educativa) determinante. A construção da nova sociedade e, portanto, da nova escola, não pode acontecer por outra via que não seja a própria escola (Saviani, 2003). Sabemos, claro, que esta especificidade da dimensão prática da Crítica não é ponto de acordo entre os psicólogos escolares. No entanto, o esclarecimento desta posição é importante porque não podemos suspeitar que o anúncio da palavra Crítica refira-se a uma concepção unânime ou esteja livre de apropriações e utilizações diversas.
Da nossa parte, além da defesa da escola como espaço preponderante na organização e promoção do desenvolvimento humano, defendemos que o psicólogo deva integrá-la, como a única possibilidade de que sua ação seja realmente crítica. Esta defesa está baseada no princípio, oriundo da Psicologia Histórico-Cultural, de que o desenvolvimento pedagógico é um processo psicológico ao passo que o desenvolvimento psicológico só se materializa no processo pedagógico (Vigotski, 2003).

Assim, este trabalho soma-se àqueles, produzidos por psicólogos, que têm se dedicado a vivenciar a escola, incluindo-se como atores do cenário escolar, partícipes do conjunto de forças, determinações e ações que constituem o processo educativo (Machado, 2014; Rigon, Asbahr, \& Moretti, 2010). Estes psicólogos materializam a Crítica, afastando-se da posição do suposto saber que recebe queixas ou demandas encaminhadas $d a$ escola e atuam sobre o sujeito. Esta não é uma posição sectária, muito menos onipotente. É preciso que esteja claro que defender o psicólogo escolar como um profissional que atue na escola junto aos demais atores, não significa rechaçar o seu papel e a sua importância em outros espaços. Mas, significa, sim, defender que as ações desenvolvidas por eles nestes outros espaços transforma-se por meio da sua presença nas escolas.

Desta perspectiva, este trabalho compartilha a nossa vivência da escola pública brasileira e apresenta a construção de uma categoria, organizada a partir da síntese entre fundamentos da Psicologia Histórico-Cultural e da Psicologia Social da Libertação, materializadora do sentido da atuação Crítica do Psicólogo Escolar: situação-limite.

Dentre suas elaborações, a produção da Psicologia hegemônica consolidou um conjunto de conhecimentos que versam sobre o desenvolvimento humano. A ciência psicológica, desde seu surgimento, se interessou pelo estudo dos processos que caracterizam o desenvolvimento, seja enfatizando-o como uma sucessão de etapas sobrepostas seja identificando-o com seu conteúdo ou com seu produto. De maneiras distintas, estes conhecimentos forjaram explicações sobre as mudanças físicas e psicológicas que acompanham a criança desde seu nascimento.

Segundo o volume A century of developmental psychology, produzido pela American Psychological Association (APA), o conjunto de informações disponibilizado para a sustentação do entendimento sobre o desenvolvimento humano oscilava entre dois 
pólos: ora a ênfase recaía sobre as bases biológicas do comportamento e visava identificar a relação entre evolução e desenvolvimento, ora priorizava os aspectos emocionais e inconscientes do psiquismo humano que deveriam evoluir de um estado de total indiferenciação para a incorporação da sociabilidade (Parke, Ornstein, Reiser, \& Zahn-Waxler, 1994). Em ambos os casos, os estudos identificavam padrões normativos de desenvolvimento, ou seja, identificavam o que era esperado e o que não deveria acontecer, delimitando, pois, os consequentes padrões de saúde e de doença, de desenvolvimento saudável ou patológico.

Este panorama sinaliza uma questão importante: as teorias do desenvolvimento humano são apresentadas como uma compilação e não atingem uma perspectiva de análise histórica capaz de confrontar as teorias entre si e de compreendê-las a partir da realidade que as produziu. Por isso, é preciso considerar que esta foi uma produção gestada no berço da sociedade norte-americana, no interior de um contexto econômico e social específico e que, justamente por isso, estava longe de representar todos os estudos produzidos pela psicologia na área do desenvolvimento humano.

Tal constatação indica o vínculo entre a construção da ciência moderna e a organização da sociabilidade capitalista. E é exatamente a estrutura do capital que relaciona a figura da escola e a organização dos processos de desenvolvimento. Ao resgatar as circunstâncias desta história, Saviani (2003) explica que nos marcos da gênese da propriedade privada, nas sociedades feudais, quando a posse da terra ditava os rumos da economia, a escola foi criada como espaço destinado à ocupação do tempo ocioso daqueles que não precisavam trabalhar para sobreviver. Todavia, com o advento da modernidade, a terra foi deslocada da centralidade da economia e passou-se a estimular o desenvolvimento das forças produtivas. Deste modo, no berço da sociedade capitalista, no mote da industrialização, a escola passou a servir à disseminação de conhecimentos que serviam à instrumentalização da empreendedora e dominante classe burguesa.

Assim, no bojo das contradições históricas, juntamo-nos aos que defendem que a escola pode transformar a sociedade, libertando-a das agruras do capital. Afinal, a cultura acumulada pode servir tanto ao ajustamento das pessoas quanto à sua libertação e emancipação (Saviani, 2003). Por isso, dedicamo-nos à relação entre as teorias sobre desenvolvimento humano propostas pela Psicologia e a manutenção da estrutura do capital. O desconforto com esta posição hegemônica está consistentemente marcado nos escritos de Vigotski, já em 1927. Quando, nesta época, ele escreveu sobre o Significado Histórico da Crise da Psicologia, lançou as bases para um movimento de crítica e produção teórica embasado nas relações humanas historicamente constituídas, anunciando um projeto político e científico fundamentado na ontologia do ser social e, portanto, precursor da chamada Psicologia Crítica (Vigotski, 1927/1991).

Esta Psicologia Crítica Soviética começou a questionar a variedade restrita de temas que estruturava as formas e as funções das produções psicológicas que, hegemonicamente, embasavam as teorias sobre desenvolvimento humano. Estes temas abordavam os aspectos biológicos ou emocionais do desenvolvimento sem de stacar suas continuidades, aproximações ou relações. A repetição desconexa destes tópicos sinalizava não só a restrição, mas também a normatividade das temáticas que a psicologia do desenvolvimento estudava e refletia, em estreita concordância e colaboração com as ciências naturais e com as práticas ditadas por elas.

No Brasil, esta tendência já foi, incisivamente, explicada por meio da explicitação da relação entre a Psicologia e a Educação. Subjugada pelas ciências médicas, a Psicologia decidiu subjugar a Educação, anunciando-se como detentora do saber capaz de avaliar e ajustar crianças ao processo de escolarização necessário à formação e organização de sujeitos aptos a vender sua força de trabalho (Angelucci et al., 2004; Facci et al., 2006; Patto, 1984).

A ruptura com esta tendência, por outro lado, é o que tem consolidado o movimento de crítica no interior da Psicologia Escolar. Nesse sentido, desde e por meio das produções soviéticas, a Psicologia Histórico-Cultural vem sistematizando um novo método, debatendo uma nova ontologia e, assim, instaurando a contra-hegemonia na ação e elaboração de conhecimentos na interface entre a Psicologia e a Educação.

\section{Fundamentos teórico-metodológicos}

O materialismo histórico-dialético é a matriz teórico-metodológica decorrente e promotora desta crítica no interior da Psicologia Escolar. Em primeiro lugar, anunciar esta crítica significa revelar o compromisso histórico entre a Psicologia e a ordem do capital (Parker, 2007). A decorrência desta revelação, contudo, não é unívoca e, do nosso ponto de vista, é o que realmente explicita a crítica: a ação cotidiana que visa à 
transformação da sociedade desigual, injusta e opressora (Paulo Netto, 1997).

Nesse sentido, a característica central da Psicologia denominada Crítica é a unidade de um projeto teórico, metodológico e político cuja proposta prevê a reconstrução da Psicologia e da Sociedade a partir da materialidade que emana das condições reais e das demandas concretas das maiorias populares (Holzkamp, 1992). Assim, podemos concluir que a emergência do materialismo histórico-dialético como filosofia, teoria e método é a característica estruturante do projeto que vem construindo e consolidando a Psicologia Crítica.

Por isso, em princípio, é necessário entender o materialismo como uma posição filosófica dedicada à explicação da realidade. Ao esclarecer este ponto, Kosik (1969) explica que a proposição básica do materialismo se refere à existência da realidade independentemente da existência da humanidade. Ele afirma a matéria como substância primordial e essencial da realidade. Assim, a matéria produz o pensamento que é o seu produto mais elevado e a forma mais complexa da atividade humana.

Esclarecida a origem do materialismo como posição filosófica, pode-se partir para a segunda e importante colocação: é no interior da obra de Marx que o materialismo sustenta uma nova e contundente construção teórica e metodológica. Segundo acentua Paulo Netto (1997), o trabalho de Marx previa o estudo da sociedade burguesa com vistas à sua explicação $e$ consequente ultrapassagem revolucionária, na medida em que se erguia como um projeto da e para a classe operária. Acontece que, ao fazer isso, Marx ultrapassou os limites de sua proposta inicial, delimitou os pilares de uma nova concepção de mundo, construiu uma nova ontologia do ser social e erigiu os limites do materialismo histórico-dialético como filosofia, teoria e método. Esse resgate do fundamento ontológico da obra de Vigotski tem sido desvelado por valorosos esforços no interior de grupos de pesquisa brasileiros. Nesse sentido, destacamos aqueles que enfatizam a retomada conduzida por Lukács do conceito marxiano de trabalho e da sua delimitação da ontologia do ser social (Carmo, 2008).

Ao investigar a complexidade destes fundamentos, Reed (1966) apontou os desafios que se colocavam frente a esta epistemologia marxista. Perguntando-se sobre o que ela significa afinal, o autor percorre um caminho didático e explica que a concepção materialista é aquela que resgata as leis da natureza como determinantes e não como pré-determinantes das ações humanas. Isto não significa dizer que o sujeito está à mercê destas leis e que a história o condiciona, mas, exatamente o contrário: a relação do sujeito com a natureza e suas forças de produção é tão concreta que constitui a sua subjetividade, seu pensamento, sua consciência. Este sujeito ativo, então, volta a agir sobre a natureza e modifica suas leis.

Assim, absorvida pelo materialismo, a lógica dialética reconfigura a solução do problema da relação entre as leis do pensamento e as leis do mundo objetivo e revela que a atividade prático-sensorial é a base imediata do surgimento de todas as faculdades intelectuais, inclusive, do próprio pensamento. No interior do marxismo, sujeito e objeto estão unificados na história e a dialética conduz o movimento do pensamento e representa a atividade histórica do homem no mundo (Kosik, 1969).

A partir desta compreensão entende-se que a atitude primordial de homens, mulheres e crianças em face desta realidade não é a de sujeitos abstratos e meros cognoscentes, mas de sujeitos que agem objetiva e praticamente, sujeitos históricos que se relacionam com o mundo e com outras pessoas. Esta, como afirma Kosik (1969) é a realidade humano-social (e não natural) da qual o humano é produto e produtor.

Tal compreensão, portanto, reconfigura, integralmente, a compreensão da relação entre escola e desenvolvimento humano. Como uma construção humana dedicada à transmissão da cultura acumulada pela humanidade, assumimos a escola como potencial agente de transformação da realidade. E como palco da promoção organizada dos processos de desenvolvimento humano, a escola resgata e questiona o papel do psicólogo escolar. Ora, mas se o movimento de crítica mobilizado pelo materialismo histórico-dialético no interior da Psicologia Escolar discorda dos métodos utilizados pela Psicologia Hegemônica, o que ele propõe em contrapartida? A literatura produzida pela área demonstra que a indefinição do que seja a atuação crítica é um problema importante. Por isso, tomando este problema como nosso ponto de partida, dedicamonos a investigá-lo no cotidiano de nossa própria prática, no programa chamado 'Voo da Águia' que há 14 anos desenvolvemos nas escolas públicas do município de Campinas.

O 'Voo da Águia'1 é um programa gestado no interior do Programa de Pós Graduação em Psicologia da PUC de Campinas e materializado nas escolas da rede municipal de Educação Básica. Ele prevê a inserção de 
psicólogos no cotidiano das escolas, explicitando a práxis como a vivificação da crítica. É no interior da escola que o psicólogo se constitui como o profissional que avalia, acompanha e organiza ações que promovem os processos psicológicos do desenvolvimento.

\section{A Atuação Crítica}

Com este posicionamento sobre a definição da Crítica insistimos na defesa de que construir fundamentos do lado de fora é perpetuar na subjugação da Educação. É encaminhar, destituir e retirar da escola a possibilidade de agir sobre a educação. A Psicologia em si não fornece, diretamente, conclusões pedagógicas. Mas, conforme nos ensina Vigotski (2003): 'o processo de educação é um processo psicológico' (p. 41). Pedagogos e psicólogos são responsáveis por atividades diferentes, contudo, ambas constituem o processo educativo.

Logo, quando mencionamos estas diferenças referimo-nos aos objetivos de suas atividades. $\mathrm{O}$ aporte da Pedagogia Histórico-Crítica (Rigon et al., 2010) propõe que o objetivo da Educação é a organização e orientação da atividade de aprendizagem (ensino e estudo). Por sua vez, este objetivo da atividade pedagógica está sustentado pela concepção de que o objetivo da Educação é possibilitar aos sujeitos a apropriação dos conhecimentos e experiências produzidos pela humanidade ou, ensinar ao estudante um "modo de ação generalizado de acesso, utilização e criação do conhecimento, o que se torna possível ao se considerar a formação do pensamento teórico" (Moura, Araújo, Ribeiro, Panossian, \& Moretti, 2010, p. 98).

Conduzir a atividade pedagógica, entretanto, requer do educador a compreensão de que os sujeitos se desenvolvem imersos em relações sociais e históricas determinadas e de que o ensino, como relação interpsíquica, orienta e reconfigura os rumos do desenvolvimento ao longo de um processo psicológico. Segundo a concepção de Moura et al. (2010), baseada na Teoria da Atividade, a atividade de ensino e a atividade de estudo compõem uma unidade dialética:o objeto a ser ensinado deve ser compreendido pelos estudantes como objeto de aprendizagem. A necessidade de apropriação da cultura constitui motivos que orientam a atividade de ensino e estudo e o motivo de ambas deve coincidir para que a aprendizagem seja concretizada.

Ao explicitar que a estrutura e a dinâmica do desenvolvimento das funções psicológicas superiores acontece imerso em determinadas situações sociais de desenvolvimento, Vigotski (1932/2006) anuncia a dependência do desenvolvimento das funções psíquicas em relação aos processos educativos. Nesse sentido, podemos dizer que o que é condição para a atividade psicológica é objeto da atividade pedagógica ou que o desenvolvimento pedagógico é um processo psicológico e que o desenvolvimento psicológico só se materializa no desenvolvimento pedagógico. As atividades de ensino e estudo formalizadas pela escola promovem o desenvolvimento do psiquismo da criança. Todavia, o desenvolvimento psíquico constituído como um drama psicológico é o que possibilita a construção da aprendizagem.

Segundo a elaboração de Vigotski (1932/2006), o processo de desenvolvimento acontece ao longo dos chamados períodos de idade. Cada período constitui um todo único, cujas leis internas regem a constituição de sua estrutura e dinâmica de funcionamento. Chama-se de estrutura às formações globais e qualitativamente novas que surgem em cada período de idade por meio de transformações psíquicas e sociais que se produzem pela primeira vez ao longo do processo (como a aquisição da fala, por exemplo). A dinâmica por sua vez é entendida como o movimento do processo, como orientadora da relação entre as unidades estruturais. Ela é o conjunto de leis que norteia o funcionamento das estruturas como um sistema integrado.

Isto significa que ao longo dos períodos de idade, o processo de desenvolvimento segue um curso lento, de transformações moleculares na sua relação com o meio, até que o acúmulo destas transformações microscópicas atinge um limite máximo que culminam na formação de uma estrutura qualitativamente nova. Esta estrutura inaugura uma crise na medida em que altera a possibilidade da relação já estabelecida entre a criança e o meio: "desarrolla de forma brusca, impetuosa, que adquiere em ocasiones, carácter de catástrofe" (Vigotski, 1932/2006, p. 256).

Segundo depreendemos das elaborações de Vigotski (1932/2006), a crise é a própria tensão entre o social e o pessoal, é o encontro entre o objetivo e a produção de subjetivações, é o momento em que este movimento de natureza dialética modifica a estrutura da personalidade do sujeito e, assim, altera, reorganiza e delimita novas possibilidades para o curso do desenvolvimento.

Nesse sentido, a vivência do drama escolar e de suas crises só é possível se todos os atores do processo educativo ocupam o cenário da escola. E, se as situações sociais vivenciadas na escola são fonte do processo de 
desenvolvimento, elas também são fonte para a ação dos profissionais que desejam promover as máximas possibilidades deste desenvolvimento. Somente vivenciando-as podemos identificar seus limites, determinantes e possibilidades.

\section{Situações-limite e Ações limite}

Se a ideia de situação social de desenvolvimento foi desenvolvida por Vigotski, a ideia de situaçãolimite foi elaborada por Ignacio Martín-Baró. Ele foi um psicólogo social e jesuíta espanhol que participou ativamente da longa guerra civil que atingiu El Salvador durante 12 anos. Por meio de sua formação teológica, filosófica, política e psicológica, ele desenvolveu um rico estudo sobre as contradições sociais, o contexto da guerra, seus condicionamentos históricos, estrutura política e a contraposição de suas consequências objetivas e subjetivas para a constituição do psiquismo humano (Ibáñez, 1998).

Este estudo desenvolveu e consolidou a Psicologia Social da Libertação como epistemologia dedicada à compreensão da relação indivíduo e sociedade, à análise das formas de organização dos grupos e dos conflitos existentes no âmbito das complexas e, por vezes injustas, relações econômicas, políticas e sociais. A ideia de libertação, decorrente desta formulação, pode ser entendida como condição e como fim, como objeto e como objetivo, que visa à busca pela superação destas condições sociais opressivas e luta pelo estabelecimento de relações interpessoais emancipadas (Martín-Baró, 1990a).

O trabalho construído por Martín-Baró (1990a,1990b) toma forma a partir da sua vivência da situação de guerra. Desta prática viva, por meio do que ele chamou de realismo-crítico e dialética-histórica, a Psicologia Social da Libertação construiu conceitos coerentes com a nossa realidade. Fundados na prática e destinados à prática, estes conceitos exigem que reflitamos sobre a sua potencialidade para a construção da ação psicológica na (nova?) realidade da América Latina.

A precariedade das condições de vida e o contato íntimo com a violência e com o medo o levaram a refletir sobre o desenvolvimento humano como um processo que acontecia circunstanciado por eventos extremos. Neste contexto, a sua atenção voltou-se, especialmente, para o desenvolvimento das crianças e os seus esforços foram direcionados para o propósito de entender os movimentos e as imbricações deste processo. Aí, a partir das produções de Paulo Freire (1969/2005), Martín-Baró (1990a,1990b) apropria-se do conceito de situaçãolimite. Utilizando-se da matriz marxiana no interior da elaboração da sua teoria psicológica, ele problematiza as ideias de Paulo Freire explicando as situações-limite como eventos concretos que refletem a relação entre o sujeito e o meio, seus determinantes e possibilidades de mudança (Martín-Baró, 1990a, 1990b).

Insatisfeito com os recursos produzidos no interior da psicologia hegemônica, originárias de um modelo liberal e positivista, cujas forças sustentavam, inclusive, a guerra que destruía o país que ele escolheu para viver, Martín-Baró (1990a, 1990b) questionou a utilidade da ciência psicológica que deveria mitigar o sofrimento humano, mas que, muitas vezes, contribuía com a sua produção e manutenção quando se dedicava à produção de constructos teóricos que acabavam por aprisionar os sujeitos na irrefutabilidade da doença.

$\mathrm{Na}$ busca pelo rompimento com este modelo e decidido a não condenar aqueles sujeitos, principalmente as crianças, ao desenvolvimento de psicopatologias como a ciência psicológica de então apregoava, ele propôs um caminho alternativo para a compreensão do que seria a saúde mental. Para cumprir seus propósitos, ele discutiu as concepções teóricas não hegemônicas que surgiam no âmbito da Psicanálise, da Pedagogia, da Psiquiatria e da Filosofia sob a forma de questionamentos ao modelo vigente.

Nesse sentido, ele sugere que o conceito de situação-limite remonta à compreensão do filósofo brasileiro Álvaro Vieira Pinto. Ao explicar que concebe a prática da educação libertadora como possibilidade de promover o desenvolvimento dos homens em situação ele explicita sua visão intrinsecamente histórica do homem social, ativo e consciente cujo contato dialético com o mundo é circunstanciado por situações-limite, como dimensões concretas e históricas de uma dada realidade.

Assim é que Martín-Baró (1990b) desenvolve como categoria psicológica uma ideia que está colocada como categoria sociológica. Coerente com sua opção de vida e com a força de quem não dissocia as propostas de atuação profissional da realidade em que elas tomam forma, Martín-Baró (1990a, 1990b) explicitou o seu vínculo com a epistemologia marxista e enfatizou que os limites devem ser reconhecidos e considerados. Todavia, ele os concebeu como processos vivos e imersos nas relações que as crianças constroem com o mundo ou que o mundo constrói com as crianças e não como 
fatores externos, determinantes de um desenvolvimento adoecido e fadado ao insucesso. Portanto, o conceito de situação-limite se configura como uma aposta nos sujeitos e nos coletivos que os constituem.

Da nossa parte, o que temos feito é contrapor a epistemologia construída por Martín-Baró àquela elaborada por Vigotski. Esta relação sustenta-se no bojo da ontologia partilhada por ambos. Desta perspectiva, os conceitos de crise e situação-limite enfatizam as ações cotidianas dos sujeitos, tanto como fonte dos processos de desenvolvimento, quanto das propostas de intervenção profissionais dedicadas a estes processos.

Do ponto de vista teórico, se a Psicologia HistóricoCultural resgata um projeto ético-político que questiona a Psicologia hegemônica no mundo todo, a Psicologia Social da Libertação imprime as marcas da América Latina a este questionamento. Assim, da nossa vivência do cotidiano da escola, mediada por este contraponto, temos definido as situações-limite como ações, eventos ou práticas que, segundo o ponto de vista das crianças ou dos demais sujeitos do cenário escolar, prejudicam, impedem ou dificultam o desenvolvimento da criança, afetando-a criticamente.

Ao explicarmos as situações-limite (MartínBaró, 1990a, 1990b) como aquelas que afetam o desenvolvimento das crianças de forma crítica, não o estamos descaracterizando como um processo relacionado a circunstâncias múltiplas. Ao contrário, apenas estamos enfatizando a intensidade de determinadas situações e as possibilidades que elas guardam para o curso deste processo. Uma situação crítica, apesar de sua manifestação ou aparência de prejuízo ou dificuldade, não necessariamente significa um desfecho negativo.

Da síntese possível entre o conceito de situaçãolimite na Psicologia Social da Libertação e o conceito de crise na obra de Vigotski entendemos que a crise ou o limite, na relação com o outro, são momentos que afetam e, assim, descortinam possibilidades de desenvolvimento e vida (Martín-Baró, 1990a, 1990b; Vigotski, 1932/2006). Logo, concluímos que identificar situações-limite e promover ações-limite é a essência que define a atuação crítica do psicólogo escolar. Estar na escola, portanto, é a materialidade que o permite vivenciar situações-limite e conduzir ações-limite. A partir deste pressuposto, este trabalho apresenta o método que desenvolvemos, à luz do materialismo histórico-dialético para evidenciar o que significa a atuação crítica em Psicologia Escolar.

\section{Método}

Este método é fruto da ação que vimos desenvolvendo no interior 'Voo da Águia'. Por meio dele, ao longo dos últimos quatro anos, atuamos em uma Escola Municipal de Ensino Fundamental (EMEF) no município de Campinas. Em razão de uma decisão metodológica, resultante do reconhecido esforço das pesquisas em ciências sociais, desenvolvemos o que chamamos de pesquisa-ação-participação (Walter, 2010). Nesta proposta, intervenção e investigação compuseram uma unidade que nos permitiram as sínteses que compartilhamos aqui.

Assumir nossa relação com a realidade pesquisada é assumir que não consideramos a possibilidade de observar silenciosamente, descrever simplesmente e concluir arbitrariamente sobre o que acontece dentro da escola. Assim, propusemos a categoria situação-limite como estruturante da atuação do psicólogo na escola e consideramos que esta pesquisa se debruçou sobre a nossa própria conduta e, sobretudo, sobre a conduta que construímos e reconstruímos com crianças, pais, mães, avós, tios, professores, orientadores, supervisores e diretores ao longo de nossa interação cotidiana dentro da escola. Obviamente que este lugar pressupõe a existência de um vínculo que sustenta e permite a instauração de uma relação de confiança ou, pelo menos, de respeito. Logo, a um só tempo, construímos como intervenção o que investigamos por meio da pesquisa. Do mesmo modo, incorporamos as conclusões da pesquisa para, de fato, modificar a intervenção.

A vivência do cotidiano extrapolava o alcance da pesquisa e, por isso mesmo a modificava de outras formas. A convivência real ultrapassava o que poderíamos imaginar apreender com o recurso de instrumentos ou técnicas específicas. Se os vínculos eram elaborados por meio das conversas que nos aproximavam (ou nos afastavam) ao longo das relações que construíamos diariamente, a palavra se revelava como a ferramenta mais fiel ao registro do que a convivência significava. Por isso, notas escritas em diários de campo foram a técnica que escolhemos como possibilidade de materializar o vivido e refletir sobre seus sentidos (Brandão, 1982).

Ao refletir sobre como a atuação do psicólogo na escola se constitui, devemos acentuar que ela é delimitada pelos processos de pensamento e fala que a caracterizam ao longo de sua relação com os demais atores do cenário escolar (Vigotski, 1934/2001). Os diários de campo, como registros da intervenção e 
instrumentos da pesquisa contêm elementos de fala e de pensamento que conduzem a interação entre o psicólogo e os outros sujeitos, os elementos das cenas que compartilhamos no cenário escolar. Assim, os diários de campo constituem-se como sínteses das várias ações desenvolvidas dentro da escola por meio de processos de pensamento e fala: participação nas salas de aula, reunião de professores, famílias e gestores, espaços de formação, conversas com crianças, professores, famílias e orientadores pedagógicos e visitas domiciliares.

Dessa forma, a construção dos diários de campo ultrapassa a condução de uma atividade meramente descritiva para constituir a materialização da nossa vivência dentro da escola. Os processos de pensamento e fala delimitam a sua construção, e o reconhecimento das dimensões subjetivas que envolvem estes processos tornam-se também objetos de pesquisa. Os diários de campo revelam nossa relação com os sujeitos do espaço escolar e, portanto, são reveladoras das ações que caracterizam a atuação do psicólogo escolar. Se estas ações são conduzidas com o recurso de palavras, acentuamos que elas podem ser potencializadas por meio da identificação de situações-limite e, assim, contribuir com a busca pelas máximas possibilidades de desenvolvimento dos sujeitos.

No Manuscrito de 1929, Vigotski explicita as bases da Psicologia Concreta do Homem e enfatiza a noção de drama como um ato de decisão humana sobre a condução do seu destino histórico (Vigotski, 2001). Ao resgatá-lo, Delari Jr. (2011) investiga os sentidos do drama no interior desta perspectiva. E é esta posição, que assume o drama como concepção teórica, que fundamenta nossa decisão metodológica.

Ao delimitar como objetivo do seu trabalho a busca pelas contribuições das artes para a psicologia, Delari Jr. (2011) retoma uma citação de Politzer segundo a qual a psicologia deveria retornar à vida imitando o teatro. Nas palavras do autor, a psicologia concreta poderia imitar o teatro "vindo, talvez, a nos apresentar uma realidade viva que nos diga respeito, na qual nos reconheçamos e que, principalmente, permitanos transpor nossos próprios limites" (p. 183). Neste trabalho, o autor reflete sobre o verbo 'drân,' oriundo da literatura grega para designar um tipo de 'fazer': o 'fazer' inconcluso, em processo, cujos modos de agir e resultados não são predeterminados, uma vez que estão relacionados com o agente da ação.

Nossa concepção de que, na escola, o psicólogo propõe ou executa determinadas ações capazes de afetar o desenvolvimento das crianças instaura o nosso desafio metodológico: buscamos, nas notas escritas nos diários de campo, unidades capazes de delimitar as cenas em que o psicólogo atuava com este objetivo. Mas como investigar as cenas sem destituí-las da totalidade que as contém? Como perscrutar os sentidos contidos nas palavras escritas a partir de vivências complexas?

Da possível e já anunciada relação da Psicologia com o drama, inspiramo-nos no teatro para construir procedimentos para a análise do conteúdo dos diários de campo. No palco da vida escolar, crianças, professores e pais encenam histórias reais. Por um lado, estas cenas cotidianas constroem o tecido de relações sociais concretas que se constituem como fonte de desenvolvimento. Por outro lado, cenas de uma história singular estão contidas em atos específicos, vividos por personagens específicos. Daí, acentuamos que extrair atos dos diários e cenas dos atos sem destituí-los da conexão íntima que os relaciona seria o mote da nossa trajetória metodológica.

Da literatura das artes dramáticas, recuperamos o Dicionário de Teatro de Patrice Pavis (1999), com o intuito de nos aproximarmos das definições de ato, ator, ação e cena, importantes para a estruturação da nossa análise. Ao apresentar seus 560 verbetes, o autor sintetiza e discute questões da dramaturgia, encenação, estética e semiologia. Segundo a síntese que fizemos da sua elaboração, entendemos que ato é a divisão externa da peça em partes marcadas pelo desenrolar da ação. A ação é o conjunto de processos e transformações visíveis promovidos pelo ator. $O$ ator é o corpo condutor da ação e situa-se no cerne do acontecimento teatral, ou seja, da cena. A cena é a unidade temática da ação. O tema é o resumo da ação, sua ideia central ou seu princípio organizador.

Da perspectiva da interface a que nos propusemos para a organização do método de análise, podemos dizer que atos estão contidos nos diários de campo como parte de uma história encenada no cotidiano da escola. Um ato é marcado, especialmente, por uma ação ou situação protagonizada por um ator na relação com outras ações e outros atores. Assim, tomamos a situação-limite como unidade de análise para estruturar os atos. Tendo destacado um ato, identificamos, no seu conteúdo, temas que, por sua vez, delimitam as cenas. Tomando, mais uma vez, a situação-limite como unidade de análise analisamos as cenas ao longo das situações de desenvolvimento no cenário da escola. Deste modo, considerando o desenrolar do ato, observamos a sua 
dinâmica, considerando a cena, observamos a sua singularidade.

Quanto à identificação dos sentidos que as palavras guardam sobre o conteúdo das ações que elas expressam, Vigotski (1934/2001) se detém sobre a dimensão interna da palavra e explicita as noções de sentido e significado. O sentido de uma palavra é ilimitado e o significado é apenas uma de suas zonas. Então, a palavra é fonte inesgotável de novos sentidos. Por isso, o método proposto pelo autor indica que a busca pelos sentidos só pode acontecer quando nos propomos a participar das relações que o sujeito estabelece ao longo de suas interações cotidianas qualquer que seja o contexto em que elas se desenvolvem.

Deste entendimento, reiteramos nossa convicção sobre a consideração dos diários de campo como nossa principal fonte de informações. Eles guardam, nas palavras escritas, os sentidos e significados das relações das pessoas no cenário escolar, das quais participamos ativamente. Estas relações, por sua vez, constituem-se ao longo de suas ações cotidianas na realidade da escola. Se o nosso objetivo, todavia, diz respeito à especificidade das ações do psicólogo escolar junto aos demais atores, interessa-nos demonstrar que as ações desenvolvidas por ele resultam de um processo de reflexão que a constitui consciente e intencionalmente. Ele age como pessoa no drama da vida escolar cotidiana e age como pessoa-profissional ao extrair delas outras ações determinantes da sua intervenção. Esta especificidade, portanto, anuncia nosso percurso metodológico. A tarefa desta pesquisa foi extrair das situações diárias as ações intencionais do psicólogo, explicando-as como açõeslimite e demonstrando que por mais que a atuação do psicólogo se construa no e para o cotidiano, ela não é assistemática e tampouco irrefletida.

Por meio desta concepção, analisamos 48 diários de campo e, tomando a categoria situação-limite como unidade de análise, construímos um modelo capaz de enfatizar as cenas que se desenrolavam no interior de atos específicos, as ações-limite que se desprendiam de cada cena para constituir a cena seguinte e, assim, a dinâmica de cenas que constrói o desenvolvimento da criança na escola. Do mesmo modo, enfatizamos a especificidade da ação do psicólogo escolar na relação com a especificidade das ações dos demais atores. Do total de 11 atos que delimitamos e que podem ser consultados no nosso trabalho de tese, aqui priorizamos a apresentação, breve e necessária que deve ser ilustrada com um ato sintético, logo abaixo, no figura 1.
Esta opção nos permite, aliar à ilustração, explicações sobre a construção do drama psicológico como método delimitador da atuação crítica do psicólogo escolar.

\section{Conclusões}

Gostaríamos que o leitor observasse que a evolução das cenas que compõem o ato significa também a evolução das ações-limite que as acompanham. Podemos dizer que, imerso em uma situação social de desenvolvimento, ao identificar uma situação-limite o psicólogo identifica uma situação cuja estrutura constitui determinantes para a qualidade do desenvolvimento subsequente. A identificação da situação-limite requer que o psicólogo esteja ativamente inserido no contexto da vida escolar, relacionando-se integralmente com seus atores. Essa imersão, a um só tempo, possibilita a identificação da situação-limite e delimita a construção de um panorama que formaliza as ações seguintes.

Isso significa que o horizonte que orienta a intervenção do psicólogo é a manutenção, busca ou promoção de condições favoráveis de desenvolvimento para as crianças. Obviamente, que condições favoráveis de desenvolvimento para as crianças exigem condições favoráveis de desenvolvimento para o professor, para as famílias e para os demais atores. Assim, ao identificar uma situação-limite, o psicólogo mapeia as possibilidades de suas ações futuras e traça um plano orientado e integrado com os atores e o cenário. A construção do plano não indica controle ou previsibilidade, mas delimita uma postura, um olhar e uma disposição que passam a perpassar todos os espaços e relações em que ele estiver inserido. Logo, a despeito das transformações conjunturais ou pessoais, as ações-limite são aquelas que conduzem a orientação do plano.

Neste caso, as ações-limite significaram a ênfase sobre os vínculos com pessoas importantes dentro da escola bem como sobre a relação entre esses vínculos e os sentidos que a criança produz sobre a escola. Por isso, é importante observar que as ações-limite conduzidas por nós não são atribuições exclusivas do psicólogo e não resultam de um processo solitário e arbitrário. De todo modo, esta sutileza não descaracteriza a atuação do psicólogo escolar. Ao contrário revela sua essência coletiva e participativa com absoluta clareza. Logo a apreciação das ações-limite e das dinâmicas instauradas entre elas nos permite refletir sobre o que define a intervenção do psicólogo no contexto da escola: a sua aparente invisibilidade por vezes esconde a riqueza de sua sistematização teórica e metodológica (Moreira, 2010). 


\begin{tabular}{|c|c|c|}
\hline \multicolumn{3}{|c|}{ Ato 1: O que se perde enquanto os olhos piscam } \\
\hline Cena 1 & \begin{tabular}{|c|} 
Ações-Limite \\
\end{tabular} & Cena 2 \\
\hline $\begin{array}{c}\text { Professora de educação especial } \\
\text { conversa com P/P sobre um bilhete que } \\
\text { ela recebera de uma professora do } 1^{\circ} \\
\text { ano, apresentando uma das crianças de } \\
\text { sua sala, um garoto de } 7 \text { anos que ele } \\
\text { descreve como hostil porque, segundo } \\
\text { ela, ele bate nas outras crianças; } \\
\text { P/P e professora de educação especial } \\
\text { conversam com a professora do } 1^{\circ} \text { ano } \\
\text { sobre a criança supostamente agressiva. } \\
\text { A professora diz que se preocupa com } \\
\text { o fato de que o comportamento } \\
\text { inadequado de uma criança possa } \\
\text { prejudicar todas as outras. }\end{array}$ & $\begin{array}{l}\text { P/P pergunta à professora de educação } \\
\text { especial sobre a relação que se } \\
\text { estabelece entre crianças supostamente } \\
\text { agressivas e o trabalho de educação } \\
\text { especial, argumentando que isso } \\
\text { descaracteriza tanto o trabalho do } \\
\text { educador especial como o processo } \\
\text { educativo como um todo; } \\
\text { P/P pergunta para a professora sobre o } \\
\text { que é possível observar como } \\
\text { comportamento manifesto da criança e } \\
\text { o que desconhecemos da história dela. } \\
\text { P/P sugere conversa com a criança. }\end{array}$ & $\begin{array}{l}\text { P/P conversa com a criança fora da } \\
\text { sala de aula; }\end{array}$ \\
\hline Ações- Limite & Cena 3 & Ações-Limite \\
\hline $\begin{array}{l}\text { P/P sugere um desenho e a criança fala } \\
\text { sobre sua família; } \\
\text { P/P incentiva a criança a dizer como se } \\
\text { sente e ela diz que está triste porque os } \\
\text { colegas na sala o ximgam e, por isso, } \\
\text { ele bate neles }\end{array}$ & $\begin{array}{c}\text { P/P conversa com a professora da } \\
\text { classe e com a professora de educação } \\
\text { especial sobre suas impressões sobre a } \\
\text { conversa com a criança; } \\
\text { A professora da classe reitera sua } \\
\text { preocupação sobre não permitir que os } \\
\text { comportamentos de uma criança } \\
\text { atrapalhem a turma toda e sobre sua } \\
\text { hipótese de que a criança seja } \\
\text { negligenciada pela mãe. }\end{array}$ & $\begin{array}{c}\text { P/P questiona sobre a professora } \\
\text { sobre como podemos determinar o } \\
\text { que significa o sofrimento de uma } \\
\text { criança e de todas as crianças; } \\
\text { P/P argumenta que a família está } \\
\text { distante da escola e que a escola } \\
\text { também deve se implicar com isso } \\
\text { para que não produza ações } \\
\text { baseadas em suposições; } \\
\text { P/P sugere que a professora convide } \\
\text { a mãe da criança para uma conversa } \\
\text { e se disponibiliza a participar da } \\
\text { conversa e ela concorda. }\end{array}$ \\
\hline Cena 4 & Ações- Limite & Cena 5 \\
\hline $\begin{array}{c}\text { P/P e professora conversam com a } \\
\text { mãe; } \\
\text { P/P fala do Voo da Águia e dos } \\
\text { objetivos da Equipe de Psicologia na } \\
\text { escola, ressaltando a importância de } \\
\text { conhecermos as crianças e suas } \\
\text { famílias; } \\
\text { Mãe fala sobre sua rotina e a rotina dos } \\
\text { seus filhos em casa. Diz que tem } \\
\text { trabalhado muito e que isso a tem } \\
\text { afastado das crianças e do cuidado com } \\
\text { a alimentação e com as roupas delas. } \\
\text { Falou que as crianças também sofriam } \\
\text { com a ausência do pai, de quem ela se } \\
\text { separara recentemente; } \\
\text { Mãe fala sobre a importância do } \\
\text { contato da escola e diz que vai estar } \\
\text { mais atenta às expressões do filho e ao } \\
\text { contato com a escola }\end{array}$ & $\begin{array}{c}\text { P/P conduz a conversa, falando para a } \\
\text { mãe sobre como vemos a criança na } \\
\text { escola, sobre como ela tem se } \\
\text { relacionado com os colegas na sala de } \\
\text { aula; } \\
\text { A professora fala para a mãe sobre o } \\
\text { histórico do seu convívio com a } \\
\text { criança, descrevendo-o como uma } \\
\text { criança doce, mas que, ultimamente, } \\
\text { demonstrava sinais de cansaço e } \\
\text { irritação; } \\
\text { P/P argumenta fala com a mãe sobre a } \\
\text { importância da sua proximidade com a } \\
\text { criança e da escola com a família, } \\
\text { enfatizando a importância de que } \\
\text { ambas se dedicassem às necessidades e } \\
\text { ao desenvolvimento da criança. }\end{array}$ & $\begin{array}{c}\text { P/P conversa com a professora } \\
\text { sobre a criança e ela se diz } \\
\text { espantada com a mudança que } \\
\text { observara no comportamento da } \\
\text { criança; } \\
\text { Conversamos sobre o conteúdo das } \\
\text { nossas ações e da nossa } \\
\text { aproximação da criança e da sua } \\
\text { família e sobre o que isso significa } \\
\text { para a vivência da criança na } \\
\text { escola. }\end{array}$ \\
\hline
\end{tabular}

Figura 1. Delimitação das Cenas que Compõem o Ato 1 e Ilustram a Atuação do Psicólogo Escolar. 
Tomando a escola como referência da nossa ação, conduzimos ações que enfatizam a singularidade da criança no seu processo de desenvolvimento e avançamos para as suas particularidades e universalidades possíveis. As ações organizadas ao longo destas dimensões as caracterizam como ações de avaliação e intervenção. Estando dentro da escola, avaliamos e intervimos em processos de percepção, pensamento, construção de vínculos, formação de conceitos e sentimentos que estruturam, promovem ou mantêm situações favoráveis ou desfavoráveis aos processos de ensino e aprendizagem desenvolvidos na escola.

\section{Referências}

Angelucci, C. B., Kalmus, J., Paparelli, R., \& Patto, M. H. S. (2004). O estado da arte da pesquisa sobre o fracasso escolar (1991-2002): um estudo introdutório. Educação e Pesquisa, 30(1). doi: 10.1590/ S1517-97022004000100004

Brandão, C. R. (1982). Diário de Campo: a antropologia como alegoria. São Paulo: Brasiliense.

Carmo, F. M. (2008). Vigotski: um estudo à luz da centralidade ontológica do trabalho (Tese de Doutorado). Recuperado de http://www. repositorio.ufc.br/handle/riufc/3165

Delari Jr., A. (2011). Sentidos do "drama" na perspectiva de Vigotski: um diálogo no limiar entre a Arte e a Psicologia. Psicologia em Estudo, 16(2), 181-197. doi: 10.1590/S1413-73722011000200002

Facci, M. G., Eidt, N. M., \& Tuleski, S. C. (2006). Contribuições da teoria histórico-cultural para o processo de avaliação psicoeducacional.Psicologia USP, 17(1), 99-124. doi: 10.1590/S010365642006000100008

Freire, P. (2005). Pedagogia do oprimido. Rio de Janeiro: Paz e Terra. (Obra original publicada em 1969)

Guzzo, R. S. L. (2007). Escola amordaçada - compromisso do psicólogo com esse contexto. In A. M., Martínez (Org.), Psicologia escolar e compromisso social. (pp. 17-29). Campinas: Alínea.

Holzkamp, K. (1992). On doing Psychology critically. In I. Parker (Org.), Critical Psychology (pp. 77-88). Nova lorque: Routledge.

Ibáñez, L. C. (1998). Compromiso y ciencia social: el ejemplo de Ignacio Martín-Baró (Tese de Doutorado). Recuperado de: http://www.uca. edu.sv/facultad/chn/c1170/testo.html

Kosik, K. (1969). Dialética do concreto. (C. Naves \& A. Toríbio, Trads.). Rio de Janeiro: Paz e Terra.

Machado, A. M. (2014). Exercer a postura crítica: desafios no estágio em Psicologia Escolar. Psicologia Ciência e Profissão, 34(3), 761-773. doi: 10.1590/1982-3703001112013

Martín-Baró, I. (1990a). La violência política y la guerra como causas del trauma psicosocial em El Salvador. In I. Martín-Baró (Org.), Psicología social de la guerra: trauma y terapia. (pp. 9-12). San Salvador: UCA Editores.
Martín-Baró, I. (1990b). Guerra y trauma psicosocial del niño salvadoreño. In I. Martín-Baró (Org.), Psicología social de la guerra: trauma y terapia. (pp. 35-39). San Salvador: UCA Editores.

Moreira, A. P. G. (2010). Situação-limite na Educação Infantil: contradições e possibilidades de intervenção (Dissertação de Mestrado) Recuperado de http://www.bibliotecadigital.puc-campinas.edu.br/ tde_arquivos/6/TDE-2011-02-07T073429Z-1650/Publico/Ana\%20 Paula\%20Gomes\%20Moreira.pdf

Moura, M. O., Araujo, E. S., Ribeiro, F. D., Panossian, M. L., \& Moretti, V. D. (2010). A atividade orientadora de ensino como unidade entre ensino e aprendizagem. In M. O. Moura (Org.), Atividade pedagógica na teoria histórico-cultural (pp. 81-109). Brasília: Liber Livro.

Parke, R. D., Ornstein, P. A., Reiser, J. J., \& Zahn-Waxler, C. (1994) The past as a prologue: an overview of a century of developmental psychology. In R. D. Parke (Org.), A century of developmental psychology. (pp. 1-70). Washington: American Psychological Association.

Parker, I. (2007). Critical psychology: what it is and what it is not Social and Personality Psychology Compass, 1(1), 1-15. doi: 10.1111/j.1751-9004.2007.00008.x

Patto, M. H. S. (1984). Psicologia e Ideologia - uma introdução crítica à Psicologia Escolar. São Paulo: Queiroz.

Paulo Netto, J. P. (1997). Relendo a teoria marxista da história. Anais do IV Seminário Nacional de Estudos e Pesquisas "História, Sociedade e Educação no Brasil". Faculdade de Educação da Unicamp.

Pavis, P. (1999). Dicionário de Teatro. São Paulo: Perspectiva

Reed, E. S. (1966). The challenge of historical materialist epistemology. In I. Parker (Org.), Critical psychology (pp. 7-20). Nova Iorque: Routledge (2011).

Rigon, A. J., Asbahr, F. S. F., \& Moretti, V. D. (2010). Sobre o processo de humanização. In M. O. Moura (Org.), Atividade pedagógica na teoria histórico-cultural (pp. 13-44). Brasília: Liber Livro.

Saviani, D. (2003). A pedagogia histórico-crítica e a educação escolar In D. Saviani (Org.), Pedagogia histórico-crítica: primeiras aproximações. (pp. 87-103). Campinas: Autores Associados.

Tanamachi, E. R. (2007). A psicologia no contexto do materialismo histórico dialético: elementos para compreender a psicologia histórico-cultural In M. E. M. Meira \& M. G. D. Facci (Orgs.), Psicologia histórico-cultural contribuições para o encontro entre a subjetividade e a educação (pp. 63-92). São Paulo: Casa do Psicólogo.

Vigotski, L. S. (1991). El significado histórico de la crisis de la Psicología. In L. S. Vigotski (Org.), Obras escogidas (Tomo I. pp. 257-407) Madrid: Visor y Ministerio de Educación y Ciencia. (Obra original publicada em 1927)

Vigotski, L. S. (2001). El problema y el método de investigación. In L. S. Vigotski (Org.), Obras escogidas (Tomo II. pp. 15-27). Madrid: Aprendizaje y Antonio Machado Libros. (Obra original publicada em 1934)

Vigotski, L. S. (2003). Psicologia pedagógica. Porto Alegre: Artmed.

Vigotski, L. S. (2006). El problema de la edad. In L. S. Vigotski (Org.), Obras Escogidas (Tomo IV. pp. 251-273). Madrid: A. Machado Libros. (Obra original publicada em 1932)

Walter, M. (2010). Social Research Methods. Sidney: Oxford University Press.

\footnotetext{
${ }^{1}$ Para conhecer o programa em detalhes, consultar Moreira, 2010.
} 
Ana Paula Gomes Moreira, Doutora em Psicologia como Profissão e Ciência pela Pontifícia Universidade Católica de Campinas (PUCCampinas), é Professora no Curso de Pedagogia da Universidade de Mogi das Cruzes (UMC). Endereço para correspondência: Rua

Major Francisco de Paula Elias, 330, apto 24, Vila Adyana, São

José dos Campos (SP). E-mail: anapaulaa.moreira@gmail.com

Raquel Souza Lobo Guzzo, Doutora em Psicologia Escolar e do Desenvolvimento Humano pela Universidade de São Paulo (USP), Pós-Doutora em Estudos Comunitários e Prevenção pela University of Rochester (USA), é Professora Titular da Pontifícia Universidade Católica de Campinas nos cursos de graduação e pósgraduação em Psicologia, Pesquisadora do CNPq e líder do Grupo de Pesquisa: Avaliação e Intervenção Psicossocial: Prevenção,

Comunidade e Libertação. E-mail: rslguzzo@gmail.com

Recebido em 19.Mar.15

Revisado em 19.Abr.16

Aceito em 25.Mai.16 